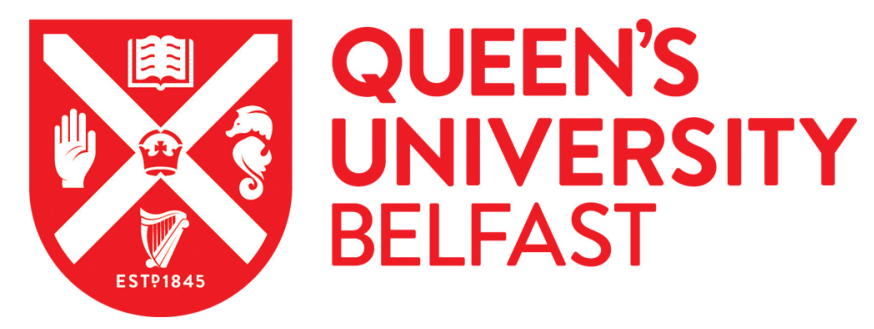

\title{
Can I Count on Getting Better? Association between Math Anxiety and Poorer Understanding of Medical Risk Reductions
}

Rolison, J. J., Morsanyi, K., \& O'Connor, P. A. (2016). Can I Count on Getting Better? Association between Math Anxiety and Poorer Understanding of Medical Risk Reductions. Medical Decision Making, 36(7), 876-886. https://doi.org/10.1177/0272989X15602000

Published in:

Medical Decision Making

Document Version:

Peer reviewed version

Queen's University Belfast - Research Portal:

Link to publication record in Queen's University Belfast Research Portal

Publisher rights

(c) 2015 The Authors

\section{General rights}

Copyright for the publications made accessible via the Queen's University Belfast Research Portal is retained by the author(s) and / or other copyright owners and it is a condition of accessing these publications that users recognise and abide by the legal requirements associated with these rights.

Take down policy

The Research Portal is Queen's institutional repository that provides access to Queen's research output. Every effort has been made to ensure that content in the Research Portal does not infringe any person's rights, or applicable UK laws. If you discover content in the Research Portal that you believe breaches copyright or violates any law, please contact openaccess@qub.ac.uk. 
1 Running head: Math anxiety and understanding medical risks

2

Jonathan J Rolison, $\mathrm{PhD}$

7 Kinga Morsanyi, PhD

Patrick O’Connor, BSc

9

13 Address for correspondence:

14 Jonathan J. Rolison

15 Department of Psychology

16 Queen's University Belfast, UK

17 David Keir Building

18 Belfast, BT7 1NN

19 Telephone: +44 (0)28 90975653

21 Word Count: 4,480

22 
Background: Lower numerical ability is associated with poorer understanding of health statistics, such as risk reductions of medical treatment. For many people, despite good numeracy skills, math provokes anxiety that impedes an ability to evaluate numerical information. Math anxious individuals also report less confidence in their ability to perform math tasks. We hypothesized that, independent of objective numeracy, math anxiety would be associated with poorer responding and lower confidence when calculating risk reductions of medical treatments. Methods: Objective numeracy was assessed using an 11-item objective numeracy scale. A 13-item self-report scale was used to assess math-anxiety. In Experiment 1, participants were asked to interpret the baseline risk of disease and risk reductions associated with treatment options. Participants in Experiment 2 were additionally provided a graphical display designed to facilitate the processing of math information and alleviate effects of math anxiety. Confidence ratings were provided on a 7-point scale. Results: Individuals of higher objective numeracy were more likely to respond correctly to baseline risks and risk reductions associated with treatment options and were more confident in their interpretations. Individuals who scored high in math anxiety were instead less likely to correctly interpret the baseline risks and risk reductions and were less confident in their risk calculations as well as in their assessments of the effectiveness of treatment options. Math anxiety predicted confidence levels but not correct responding when controlling for objective numeracy. The graphical display was most effective in increasing confidence among math anxious individuals. Conclusions: The findings suggest that math anxiety is associated with poorer medical risk interpretation, but is more strongly related to confidence in interpretations.

Key words: Risk communication; Math anxiety; Numeracy; Graphical displays; Confidence 
statistics requires a basic understanding of statistical concepts such as percentages, probabilities, and frequencies. Poor numeracy has been linked to miscalculations of health statistics. ${ }^{1-5}$ Yet for many people, despite possessing good numeracy skills, math provokes anxiety and other negative emotions that can impede reasoning about numerical information. ${ }^{6}$

The current research investigates the potential relationship between math anxiety and understanding of health-related statistical information.

As much as two thirds of adults report experiencing feelings of anxiety when faced with numerical information. ${ }^{7}$ Math anxiety, typically defined as "feelings of tension, apprehension, or fear that interferes with math performance," ${ }^{, 6}$ is often triggered by negative experiences with math education, and is moderately associated with poorer numerical ability. ${ }^{8}$ The link between math anxiety and numerical ability is perhaps partly due to a tendency for math anxious individuals to avoid math education. ${ }^{9}$ However, anxious thoughts and worries that are symptomatic of math anxiety further impede math performance by occupying limited working memory resources. ${ }^{10-13}$ Ashcraft and $\mathrm{Kirk}^{10}$ showed that performing a secondary load task whilst solving math problems was more detrimental for individuals who were high rather than low in math anxiety, suggesting that for these individuals, worries and other intrusive thoughts disrupt executive processes. Thus, beyond numeracy skills, math anxiety can have detrimental effects on people's ability to perform math tasks.

Many of the daily health choices that people make are informed by statistical claims (e.g., a toothpaste that reduces risk of tooth decay), and serious decisions about health and medical care often require that patients evaluate statistical risks and benefits associated with treatment options. ${ }^{14} \mathrm{~A}$ wealth of research has linked poor objective numeracy to 
misunderstanding of medical risks, such as risk reductions associated with medical screening $^{2-5}$ and treatment. ${ }^{15}$

However, the focus on objective numeracy skills may have neglected the role that affective factors (e.g., anxiety) play in risk communication and medical decision-making. ${ }^{16,17}$ Silk and Parrot ${ }^{18}$ found that higher scores on a math anxiety scale predicted poorer responding to numerical statements about genetically modified food risks (e.g., 'which person was most sensitive to the genetically modified soybeans?'). Math anxiety predicted poorer responding even when controlling for objective numeracy, ${ }^{18}$ suggesting that at least some of the detrimental effects of math anxiety could not be explained by numerical ability. Perhaps not surprisingly, individuals who are math anxious typically report less confidence in their ability to perform math tasks. ${ }^{19,20}$ In the health domain, nursing students who indicated higher levels of math anxiety were both more likely to fail a drug calculation test and were less confident in their ability to perform such medical calculations. ${ }^{21}$ Math anxious individuals may also be less confident in their actual responses, such as in their calculations of treatment risk reductions. This could have serious ramifications for people's real-world decision making about their health. If math anxious individuals are less confident in their understanding of the efficacy of treatment options, they may also be less willing to comply with potentially effective treatments.

In the current research, we tested for an association between math anxiety and understanding of risk reductions as a result of medical treatment. Our overarching hypotheses were that independent of objective numeracy; higher math anxiety would be associated with (a) poorer responding and (b) lower confidence when calculating risk reductions of medical treatments. 
We used two scenarios in Experiment 1: an impersonal scenario about a man who

102

faces a medical decision situation, and a personal scenario in which participants were instructed to imagine experiencing anxiety-provoking medical symptoms. People make serious decisions about their own health in situations of intense stress and anxiety (e.g., choosing among cancer treatments). Such anxiety could potentially affect correct responding to medical risk information by inducing worry, concern, and other intrusive thoughts, perhaps particularly for math anxious individuals. Including a personal scenario in Experiment 1 also enabled us to test for effects of math anxiety using study materials that are more representative than abstract scenarios of real-world medical situations.

\section{Method}

\section{Participants}

Two hundred one US participants were recruited online via Amazon Mechanical Turk (AMT) and were each compensated $\$ 0.50$. Elsewhere, the reliability, quality, and representativeness of participant data provided by AMT has been demonstrated by comparison with other recruitment methods. ${ }^{22,23}$ Table 1 provides the sample characteristics.

\section{Materials and Procedure}

Objective numeracy. Objective numeracy was assessed using the 11-item objective numeracy scale developed by Lipkus et al. ${ }^{3}$ The scale comprises three general questions that assess understanding of chance and probability (e.g., 'out of 1,000 rolls, how many times do you think a fair, 6-sided die would come up even? 2,4 , or 6'), and eight items specific to disease risk that assess ability to interpret risks (e.g., "which of the following represents the biggest risk of getting a disease? 1,5 , or $10 \%$ '), convert percentages to frequencies (e.g., 'if the chance of getting a disease is $10 \%$, how many people would be expected to get the 
disease out of 100 people) and vice versa. Responses, coded as correct (numeric value of 1) or incorrect (numeric value of 0 ), were summed across the 11 items for overall scores.

Math anxiety. Existing scales (e.g., the Mathematical Anxiety Rating Scale $[\mathrm{MARS}])^{24-27}$ assess math anxiety in educational settings (e.g., 'having to use the tables in the back of a math book') that are not applicable to adult samples. Thus, we composed the Adult Everyday Math Anxiety Scale (AEMAS) based on existing scales that would be suitable for use with individuals who are no longer in education. The AEMAS comprised 13-items that assess self-reported anxiety associated with numerical formats (e.g., 'having to work with percentages'), everyday tasks (e.g., 'having to work out prices in a foreign currency'), and the workplace (e.g., 'having to present numerical information at a work meeting'). The instructions (i.e., 'Please rate each item in terms of how anxious you would feel during the event specified'), and the rating scale were modelled on the Abbreviated Math Anxiety Scale (AMAS). ${ }^{27}$ Participants rated their self-reported anxiety for each item on a 5-point scale (1='low anxiety', 2='some anxiety', 3='moderate anxiety', 4='quite a bit of anxiety', 5='high anxiety'). Overall math anxiety scores were averaged across the 13-items.

Risk scenarios. Participants then completed two medical scenarios (see supplementary material). The first was an impersonal scenario that described a fictitious man named Jack, who visits his doctor with symptoms of numbness and pain in his leg and is informed by his physician that he has an infection caused by diabetes. Participants were told that without treatment Jack has a $60 \%$ chance that his leg will need to be amputated (i.e., the baseline risk). Participants were then informed about two treatments available to Jack, one of which was presented as an absolute risk reduction:

[Absolute risk reduction] 'Jack's chance of surviving without needing to have his leg amputated is increased $\underline{\text { TO }}$ 80\%'

The other treatment was presented as a relative risk reduction: 
[Relative risk reduction] 'Jack's chance of surviving without needing to have his leg amputated is increased $\underline{B Y} 25 \%$ '

For the baseline risk and each treatment, participants were asked: 'how many people among 1,000 like Jack will need to have their leg amputated?'. Thus, participants were required to calculate the risk that the leg would be lost on the basis of statistics about the chances of survival. This was done in order to ensure that some mental calculation was required to compute both the absolute and relative risk reductions. Participants rated their confidence in each treatment response on a 7-point scale ( $1=$ 'not at all confident', $7=$ 'very confident').

The second scenario, a personal scenario designed to evoke anxiety, asked participants to imagine:

Yesterday, whilst at home, you experienced an episode of dizziness that affected your balance. You also had a sudden loss of vision, which made you feel disorientated and fearful as you have not felt these symptoms before. Imagine what it would be like to experience these symptoms. What kind of serious medical condition might you have? Please list at least one.

$$
1 /[2 /[3 /
$$

Participants were asked to list at least one possible medical condition as a method of engaging them with the scenario. They were then asked to imagine they visit their physician with the symptoms mentioned above and are immediately referred to a neurologist, who confirms that they have had a stroke, and that without treatment they have a $70 \%$ chance of having another stroke in the near future (i.e., the baseline risk). Participants identified the baseline risk in a similar manner to the first scenario and similarly were asked to calculate the outcomes of two treatment options, one presented as an absolute risk reduction and the other as a relative risk reduction. The absolute and relative risk items were presented in a randomly generated order for each participant and each scenario provided a different set of risk 
statistics (set 1, baseline $=60 \%$, absolute $=80 \%$, relative $=25 \%$; set 2, baseline $=70 \%$, absolute $=40 \%$, relative $=50 \%$ )

Finally, participants reported how anxious they felt when reading each scenario on a sliding scale $(0=$ not at all anxious, $100=$ extremely anxious $)$ and provided their age, gender, educational level, and household income. The objective numeracy scale was completed first, followed by the math anxiety scale, and then the risk scenarios. Ethical approval was awarded by the institution ethics committee and all participants provided informed consent.

\section{Analytic strategy}

Objective numeracy scores that fell outside 1.5 times the inter-quartile range of the scale were deemed outliers. After removal of three outliers, objective numeracy scores were negatively skewed $(\bar{x}=9.68, s=10$, skewness $=-0.93$, standard error $[\mathrm{SE}]=0.17)$ and thus were negative log-transformed (skewness=0.04) for use in all statistical analyses. A random effects logit model was conducted on participants' risk responses $(1=$ correct, $0=$ incorrect $)$ to account for clustering within participants. Dummy variables were used to identify responses to the baseline and relative risk in comparison with the absolute risk. Predictors were included for objective numeracy, math anxiety, and scenario context ( $1=$ personal, $0=$ impersonal). All possible two-way interaction terms were included in a second block. Nonsignificant interactions were removed in subsequent blocks to improve model parsimony. Following a similar procedure, a random effects linear regression model was conducted on participants' ratings of confidence in their treatment responses.

\section{Results}

The mean group ratings for each of the AEMAS scale items are provided in Table 2. The overall math anxiety score $(\bar{x}=2.19, s=0.83)$ was close to the mid-point of the scale (i.e., numeric value of 2.5; indicating 'some' to 'moderate' anxiety). All the item-total correlations were positive and ranged .55 to .80 , indicating that each item correlated highly with the 
overall scale. The 13-item scale demonstrated high internal reliability (Cronbach's $\alpha=0.93$ ). Math anxiety was associated with lower objective numeracy, education, income, and being female, whereas objective numeracy was associated only with higher income (Table 3).

Manipulation check. Higher anxiety was reported for the personal scenario $(\bar{x}=42.71$, $s=31.56)$ than for the impersonal scenario $(\bar{x}=35.10, s=30.12 ; t(200)=6.17, p<.001)$.

Risk scenarios. Higher objective numeracy was associated with correct responding to the risk items $(d=0.71 \text {; Table } 4 \text { : Model 1a })^{28}$, whereas math anxiety was associated with poorer responding $(d=0.37$; Table 4 : Model 2a). Objective numeracy, but not math anxiety, predicted significantly when both were included together (Table 4: Model 3a). Participants were more likely to provide correct responses to the baseline risk (89\% correct) and less likely to provide correct responses to the relative risk ( $16 \%$ correct) in comparison to the absolute risk (49\% correct; Table 4; Model 3a). Responses were not affected by scenario context.

A minority of participants provided relative risk responses in the impersonal (20\%) and personal (26\%) scenarios that corresponded with an alternative interpretation, in which the relative risk is subtracted in absolute terms from the baseline risk. Alternative responding was not related to objective numeracy or math anxiety.

Higher objective numeracy was associated with greater confidence in risk responses, whereas math anxiety was associated with lower confidence (Table 5: Model 1a). Participants were more confident in their responses to the absolute risk $(\bar{x}=5.01, s=1.90)$ than in their responses to the relative risk ( $\bar{x}=4.69, s=1.89$; Table 5: Model 1a). Math anxiety interacted with the relative versus absolute risk items (Table 5: Model 2a), such that math anxiety was more strongly related to confidence in relative risk $(b=-0.79,95 \%$ confidence intervals $[C I]=$ $-1.05:-0.53, p<.001)$ than in absolute risk $(b=-.61,95 \% \mathrm{CI}=-0.88:-0.34, p<.001)$ responses. 
information (see Figure 1 and supplementary material) in an attempt to alleviate some of the detrimental effects of math anxiety. Graphical displays that present numerical risks visually reduce the emphasis on math information, and appear to be most effective among individuals of low numerical ability. ${ }^{2,15}$ Since math anxiety is triggered by math material, visually displaying treatment information (in addition to the numerical risks) may reduce the negative impacts of math anxiety on risk calculations and potentially increase confidence in people's responses.

In our study, we followed Galesic et al. ${ }^{15}$ and used two types of graphical displays: a smaller display with 100 icons, and a larger display with 1,000 icons (see Figure 1). Galesic et al. ${ }^{15}$ reported that people perceive medical screenings as more effective when presented in larger (i.e., out of 1,000 cases) as opposed to smaller (i.e., out of 100 cases) displays due to a ratio-bias, in which frequencies are perceived as greater for larger denominators. Although Galesic et al. ${ }^{15}$ did not assess numerical ability in this respect, individuals of lower objective numeracy and higher math anxiety may be more susceptible to such bias as a result of poorer assessment of numerical information. We employed a similar between-subjects approach to participants' responses were not affected by personalizing the medical scenario context. Thus, we did not further investigate context effects in Experiment 2. Instead, we presented participants a scenario about a fictitious cancer, known as 'Cancer D'.

Participants compensated $\$ 0.50$. Table 1 provides the sample characteristics. 


\section{Materials and Procedure}

As in Experiment 1, participants completed the 11-item objective numeracy scale developed by Lipkus et al. ${ }^{3}$ and the 13-item AEMAS to assess math anxiety.

Participants then completed a single medical scenario that asked them to imagine a patient diagnosed with a fictitious cancer, known as 'Cancer D', who has a $60 \%$ chance of dying within one year (i.e., the baseline risk; see supplementary material). Participants were informed of two treatment options, both presented as an absolute risk reduction (i.e., 'the patient's chance of surviving one year is increased TO 70\%), and for all three items were asked: 'how many patients among 1,000 who are diagnosed with 'Cancer D' will die within one year?'. Participants also rated the effectiveness of each treatment on a sliding scale $(0=$ not at all effective, $10=$ very effective) and provided a confidence rating (on a 7 -point scale; $1=$ 'not at all confident', $7=$ ='very confident') for each treatment response and effectiveness rating. The risk statistics for the two treatments were $70 \%$ and $80 \%$. It was ensured that these were presented in a counterbalanced order across participants and differed for the two treatments.

Half the participants $(n=105)$ were additionally provided a graphical display that presented visually the baseline risk out of 100 patients, the risk reduction for the first treatment (Treatment A) out of 100 patients, and the risk reduction for the second treatment (Treatment B) out of 1,000 patients (Figure 1). Finally, participants provided their demographic information. The tasks were completed in the same order as in Experiment 1 and all participants provided informed consent.

\section{Analytic strategy}

Following the procedure introduced in Experiment 1, 10 outlying objective numeracy scores were removed. After removal of outliers, objective numeracy scores were negatively skewed $(\bar{x}=9.24, s=10$, skewness $=-1.15, \mathrm{SE}=0.18)$ and thus were negative log-transformed 
(skewness=-0.13) for use in all analyses. As in Experiment 1, a random effects logit model

277

278

was used to assess correct responding to risk items in the medical scenario. A random effects linear regression model was used to analyze participants' treatment effectiveness and confidence ratings.

\section{Results}

The mean group ratings for each of the AEMAS scale items are provided in Table 2. Consistent with Experiment 1, the overall math anxiety score $(\bar{x}=2.33, s=0.88)$ was close to the mid-point of the scale (i.e., numeric value of 2.5). The item-total correlations, which were all positive, ranged .56 to .77 , and the overall scale exhibited high internal reliability (Cronbach's $\alpha=0.93$ ). Math anxiety was associated with lower objective numeracy and both math anxiety and objective numeracy were related to being female (Table 3).

Risk Scenarios. Higher objective numeracy was associated with correct responding to the risk items $(d=0.84$; Table 4 : Model $1 \mathrm{~b})$, whereas math anxiety was associated with poorer responding ( $d=0.68$; Table 4: Model $2 \mathrm{~b}$ ). Objective numeracy, but not math anxiety, predicted significantly when both were included in the same block (Table 4: Model 3b). Participants were more likely to respond correctly to the baseline risk (83\% correct) and to the Treatment B risk (79\% correct) than they were to respond correctly to the Treatment A risk (71\% correct; Table 4: Model 3b). There were no main effect of the graphical display.

Higher objective numeracy was associated with greater confidence in risk responses and math anxiety was associated with lower confidence (Table 5: Model 1b). Participants were more confident in their Treatment B responses $(\bar{x}=5.77, s=1.52)$ than in their Treatment A responses ( $\bar{x}=5.62, s=1.59$; Table 5: Model 1b). The graphical display increased confidence overall ( $\bar{x}=5.84, s=1.38$; without graphical display, $\bar{x}=5.56, s=1.63$; Table 5: Model 1b), but its effects also interacted with math anxiety (Table 5: Model 2b). Simple slope analysis revealed that the graphical display increased confidence among high math 
anxious individuals $(1 s$ below mean $=6.22,1 s$ above mean $=5.68 ; b=-0.27,95 \% \mathrm{CI}=-0.52:-$ $0.02, p=.031)$ compared to those not provided the graphical display ( $1 s$ below mean $=6.24,1$ $s$ above mean $=4.62 ; b=-0.76,95 \% \mathrm{CI}=-1.08:-0.44, p<.001)$

Treatment effectiveness. Higher objective numeracy $(b=.47,95 \% \mathrm{CI}=0.01: 0.93, p$ $=.047)$, but not math anxiety $(b=-.10,95 \% \mathrm{CI}=-0.45: 0.24, p=.551)$, predicted higher ratings of treatment effectiveness $\left(R^{2}=0.03\right)$. Lower math anxiety $(b=-.51,95 \% \mathrm{CI}=-0.75$ : $-0.27, p<.001)$ and not objective numeracy $(b=.17,95 \% \mathrm{CI}=-0.16: 0.49, p=.316)$ predicted greater confidence in treatment ratings $\left(R^{2}=0.12\right)$.

\section{Discussion}

A wealth of research in recent years has linked low objective numeracy to poorer understanding of risk reductions associated with screening and medical treatment. ${ }^{2-5}$ In the current studies, higher objective numeracy was associated with more accurate understanding of treatment risks and higher ratings of treatment effectiveness. Highly numerate individuals were also more confident in their risk calculations. Higher reported math anxiety was instead associated with poorer understanding of medical risk reductions, but not when controlling for objective numeracy. Independent of objective numeracy, math anxious individuals were less confident in their calculations of medical risks and in their ratings of the effectiveness of medical treatments.

Some types of risk information are better understood than others. For example, risk reductions are typically better understood when expressed as absolute risks (e.g., a patient's chance of surviving is increased to ... \%) than as relative risks (i.e., ... increased by... \%). ${ }^{29}$ Relative risks are also open to multiple interpretations. ${ }^{1}$ Our findings of Experiment 1 confirm that absolute risks are better understood than relative risks, and further suggest that people who are math anxious are also less confident in their calculations of relative risks than they are for absolute risks. This finding reaffirms the recommendations made by others that 
risk reductions associated with medical procedures would be best communicated by health care professionals and by the media in terms of absolute risks. ${ }^{1}$

Graphical displays are designed to reduce the burden on objective numeracy (for an example, see Figure 1). ${ }^{15}$ The one used presently was highly effective in increasing confidence among high math anxious individuals. This finding suggests that such methods may be particularly effective for boosting decision making confidence among individuals who are easily made anxious by numerical information. Using eye-tracking technology, Keller and colleagues ${ }^{30}$ showed that low numeracy individuals initially focused more on graphical as opposed to numerical risks when provided information in both formats. Highly numerate individuals showed the opposite tendency. The findings of Keller et al. ${ }^{30}$ suggest that low numeracy individuals may avoid numerical information and be attracted by graphical displays. We speculate that math anxiety among low numeracy individuals perhaps partly motivates their seeking of non-numeric formats and their avoidance of numerical formats. Math anxious individuals often report less confidence in their ability to perform math tasks. ${ }^{19,20}$ We found that such individuals were also less confident in their actual calculations of medical risk information. They were less confident also in their ratings of a treatment's potential effectiveness, which hints at a worrying possibility that self-doubt could compromise a patient's willingness to comply with effective treatments on the basis of statistical benefits. Further research may seek to explore whether low confidence among the math anxious also impacts on their willingness to engage in informed decision-making. Shared decision making is a process that aims to engage patients in decisions about their healthcare and treatment. ${ }^{31}$ Individuals of lower numerical ability are less willing to adopt an active role in the shared decision-making process. ${ }^{32}$ Math anxious people, as a consequence of their lower perceived self-efficacy, may also be reluctant to engage in active decision making about their health. 

school and college samples, which is not applicable to adults who are no longer in education. Adults face everyday tasks (e.g., 'having to work out prices in a foreign currency') as well as serious decisions about their healthcare and medical treatment, many of which make demands on one's ability to evaluate numerical information. Here, we composed a 13-item Adult Everyday Math Anxiety Scale (AEMAS) based on existing scales that could be used for adults who are no longer in education. Our analysis of the AEMAS and its association with risk calculation provides preliminary evidence that it might be used as an effective tool for assessing adult math anxiety outside of educational settings. However, the AEMAS awaits further validation and it is hoped that the current research will motivate others to explore the impacts of math anxiety on behavior in the medical domain as well as in other domains. interpretations of medical risk reductions. However, math anxiety no longer predicted significantly after partialling out effects of objective numeracy. Math anxiety and objective numeracy were highly correlated (Table 3 ; see also ${ }^{33}$ ), which raises statistical concerns about their inclusion in the same regression model. ${ }^{34}$ Nevertheless, we expected that math anxiety would have detrimental effects beyond numeracy skills. One possibility is that math anxiety indirectly impedes performance through its effects on objective numeracy. Math anxious individuals often avoid math education ${ }^{9}$ and math anxiety is related to lower perceived selfefficacy. ${ }^{19,20}$ In our investigation, math anxiety directly affected confidence in medical risk calculations. Thus, math anxiety may relate specifically to the perceived understanding of numerical risks rather than to the quality of interpretations. circumvent anxiety and stress associated with aptitude tests and traditional measures of objective numeracy. ${ }^{35}$ Subjective numeracy scales have been validated as a proxy for 
376 objective numeracy in broad age ranges. ${ }^{36}$ However, Peters and Bjalkebring ${ }^{37}$ argue that

377 subjective numeracy likely comprises multiple facets, including emotional and motivational

378 factors, in addition to actual numerical ability. In their study, positive emotional attitudes

379 toward math were more strongly related to subjective than to objective numeracy measures.

380 We speculate that math anxiety may relate closely to aspects of subjective numeracy. Hence, math anxiety may be more strongly linked to self-appraisal and motivational factors than to the quality of risk calculations. Further research may seek to explore how math anxiety relates to emotional and motivational features of subjective numeracy. Additionally, the links between math anxiety and people's willingness to engage in the process of medical decision making should further be investigated.

There are a number of potential limitations of the current research. First, math anxiety was assessed after objective numeracy. Consequently, the assessment of numerical ability may have influenced participants' subsequent math anxiety levels. This may have partly contributed to the high correlations we observed between objective numeracy and math anxiety. Ideally, math anxiety and objective numeracy would be assessed in separate testing sessions. Second, we assessed objective numeracy with the 11-item Lipkus et al. ${ }^{3}$ scale. While it is perhaps the most widely used scale for the assessment of objective numeracy, researchers have observed negative skewness on the scale, such that some scores are close to the high end of the scale. ${ }^{38,39}$ This was the case also for our current data. Our choice of objective numeracy scale may have compromised our findings. We found that math anxious individuals were more confident in their responses to absolute risks than in their relative risk responses. We did not observe parallel findings for objective numeracy that would suggest more numerate individuals have better interpretations of relative risks than absolute risks. Further studies may also consider alternative scales, such as the Berlin Numeracy Test, ${ }^{40}$ that 400 is purported to overcome these psychometric problems. Third, in Experiment 2, participants 
viewed the smaller, followed by the larger, visual format of the graphical display. Math anxious individuals characteristically avoid math information ${ }^{9}$ and so in principle could have benefited more from the larger display had it been presented first. This raises the possibility of a confounding effect of task order. Fourth, we tested participants from the general public, rather than study patients in the context that medical decision are normally made. However, many of these people will face serious decisions about their health. Finally, there are individual differences in the extent to which people are anxious about their health. Healthrelated anxiety was not measured in the present study. It is possible that health-related anxiety interacted with effects of math anxiety. Future research should aim to disentangle effects of the two types of anxiety that could both influence health-related decisions and risk perception. Further research may also seek to explore how math anxiety impacts on behavior among specific patient groups in medical settings, such as patients who must make decisions about real treatment options and individuals who are at risk of disease (e.g., breast cancer) and who face preventive medical procedures. The stress associated with making actual medical decisions with serious consequences for one's health may further exacerbate anxiety among people who are math anxious. We did not seek out highly math anxious individuals. Thus, our current findings may be conservative about the potential effects of math anxiety on understanding medical risks. How affective factors such as math anxiety impact on risk communication and medical decision-making is a fruitful topic for further investigations and is one that is currently under-studied.

(1)

(1)

(1)

(1)

5


1. Gigerenzer G, Gaissmaier W, Kurz-Milcke E, Schwartz LM, Woloshin S. Helping doctors and patients make sense of health statistics. Psychol Sci Publ Interest. 2007;8:53-96.

2. Lipkus IM, Peters E, Kimmick G, Liotcheva V, Marcom P. Breast cancer patients' treatment expectations after exposure to the decision aid program adjuvant online: the influence of numeracy. Med Decis Making. 2010;30:464-473.

3. Lipkus IM, Samsa G, Rimer BK. General performance on a numeracy scale among highly educated samples. Med Decis Making. 2001;21:37-44.

4. Rolison JJ, Hanoch Y, Miron-Shatz T. What do men understand about lifetime risk following genetic testing? The effects of context and numeracy. Health Psychol. 2012;31:530-533.

5. Schwartz LM, Woloshin S, Black WC, Welch GH. The role of numeracy in understanding the benefit of screening mammography. Ann Intern Med. 1997;127:966-971.

6. Ashcraft MH. Math anxiety: Personal, educational, and cognitive consequences. Curr Dir in Psychol Sci. 2002;11:181-185.

7. Burns M. Math: Facing an American phobia. 1998. Sausalito, CA: Math Solutions Publications.

8. Maloney EA, Beilock SL. Math anxiety: Who has it, why it develops, and how to guard against it. Trends cogn sci. 2012;16:404-406.

9. Hembree R. The nature, effects, and relief of mathematics anxiety. J Res Math Educ. 1990;21:33-46.

10. Ashcraft MH, Kirk EP. The relationships among working memory, math anxiety, and performance. J Exp Psychol Gen. 2001;130:224-237. 
11. Ashcraft MH, Krause JA. Working memory, math performance, and math anxiety. Psychon B Rev. 2007;14:243-248.

12. Eysenck MW, Calvo MG. Anxiety and performance: The processing efficiency theory. Cognition Emotion. 1992;6:409-434.

13. Maloney EA, Schaeffer MW, Beilock SL. Mathematics anxiety and stereotype threat: Shared mechanisms, negative consequences, and promising interventions. J Res Math Edu. 2013;15:115-128.

14. Reyna VF, Brainerd CJ. The importance of mathematics in health and human judgment: Numeracy, risk communication, and medical decision making. Learn Individ Differ. 2007;17:147-159.

15. Galesic M, Garcia-Retamero R, Gigerenzer G. Using icon arrays to communicate medical risks: Overcoming low numeracy. Health Psychol. 2009;28:210-216.

16. Reyna VF, Nelson WL, Han PK, Dieckmann NF. How numeracy influences risk comprehension and medical decision making. Psychol bull. 2009;135:943-973.

17. Peters E, Västfjäll D, Slovic P, Mertz CK, Mazzocco K, Dickert S. Numeracy and decision making. Psychol Sci. 2006;17:407-413.

18. Silk KJ., Parrott RL. Math anxiety and exposure to statistics in messages about genetically modified foods: Effects of numeracy, math self-Efficacy, and form of presentation. J Health Commun. 2014;19:838-852.

19. Morsanyi K, Busdraghi C, Primi C. Mathematical anxiety is linked to reduced cognitive reflection: A potential road from discomfort in the mathematics classroom to susceptibility to biases. Behav Brain Funct. 2014;10:31.

20. Pajares F, Urdan T. Exploratory factor analysis of the mathematics anxiety scale. Meas Eval Couns Dev. 1996;29:35-47. 
21. McMullan M, Jones R, Lea S. Math anxiety, self-efficacy, and ability in British undergraduate nursing students. Res Nurs Health. 2012;35:178-186.

22. Berinsky AJ, Huber GA, Lenz GS. Evaluating online labor markets for experimental research: Amazon.com's Mechanical Turk. Polit Anal. 2012;20:351-368.

23. Paolacci G, Chandler J, Ipeirotis PG. Running experiments on Amazon Mechanical Turk. Judgm Decis Mak. 2010;5:411-419.

24. Richardson FC, Suinn RM. The Mathematics Anxiety Rating Scale: Psychometric data. J Couns Psychol. 1972;19:551-554.

25. Hopko DR, Mahadevan R, Bare RL, Hunt MK. The Abbreviated Math Anxiety Scale (AMAS): Construction, validity, and reliability. Assessment. 2013;10:178-182.

26. Nunez-Pena MI, Suarez-Pellicioni M, Guilera G, Mercadè-Carranza C. A Spanish version of the short Mathematics Anxiety Rating Scale (sMARS). Learn Individ Differ. 2013;24:204-210.

27. Primi C, Busdraghi C, Tommasetto C, Morsanyi K, Chiesi F. Measuring math anxiety in Italian college and high school students: Validity, reliability and gender invariance of the Abbreviated Math Anxiety Scale (AMAS). Learn Individ Differ. 2014;34:5156.

28. Sánchez-Meca J, Marín-Martínez F, Chacón-Moscoso S. Effect-size indices for dichotomized outcomes in meta-analysis. Psychol Methods. 2003;8448-467.

29. Marcatto F, Rolison JJ, Ferrante D. Communicating clinical trial outcomes: Effects of presentation method on physicians' evaluations of new treatments. Judgm Decis Making. 2013;8:29-33.

30. Keller C, Kreuzmair C, Leins-Hess R, Siegrist M. Numeric and graphic risk information processing of high and low numerate in the intuitive and deliberative decision modes: An eye-tracking study. Judgm Decis Making. 2014;9:420-432. 
31. Frosch DL, Kaplan RM. Shared decision making in clinical medicine: past research and future directions. Am J Prev Med. 1999;17:285-294.

32. Hanoch Y, Miron-Shatz T, Rolison JJ, Omer Z, Ozanne E. Shared decision making in patients at risk of cancer: The role of domain and numeracy. Health Expect. In press.

33. Ma X. A meta-analysis of the relationship between anxiety toward mathematics and achievement in mathematics. J Res Math Educ. 1999;30:520-540.

34. Lynam DR, Hoyle RH, Newman JP. The Perils of partialling: Cautionary tales from aggression and psychopathy. Assessment. 2006;13:328-341.

35. Measuring numeracy without a math test: development of the Subjective Numeracy Scale. Med Decis Making. 2007;27:672-680.

36. Rolison JJ, Wood S, Hanoch Y, Liu P-J. The subjective numeracy scale as a tool for assessing statistical numeracy in older adult populations. Gerontology. 2013;59:283288.

37. Peters E, Bjalkebring P. Multiple numeric competencies: When a number is not just a number. J Pers Soc Psychol. In press.

38. Cokely ET, Kelley CM. Cognitive abilities and superior decision making under risk: A protocol analysis and process model evaluation. Judgm Decis Making. 2009;4:2033.

39. Galesic M, Garcia-Retamero R. Statistical numeracy for health: A cross-cultural comparison with probabilistic national samples. Arch Intern Med. 2010;170:462-468.

40. Cokely ET, Galesic M, Schulz E, Ghazel S, Garcia-Retamero R. Measuring risk literacy: The Berlin Numeracy Test. Judgm Decis Making. 2012;7:25-47. 
Table 1. Sample Characteristics

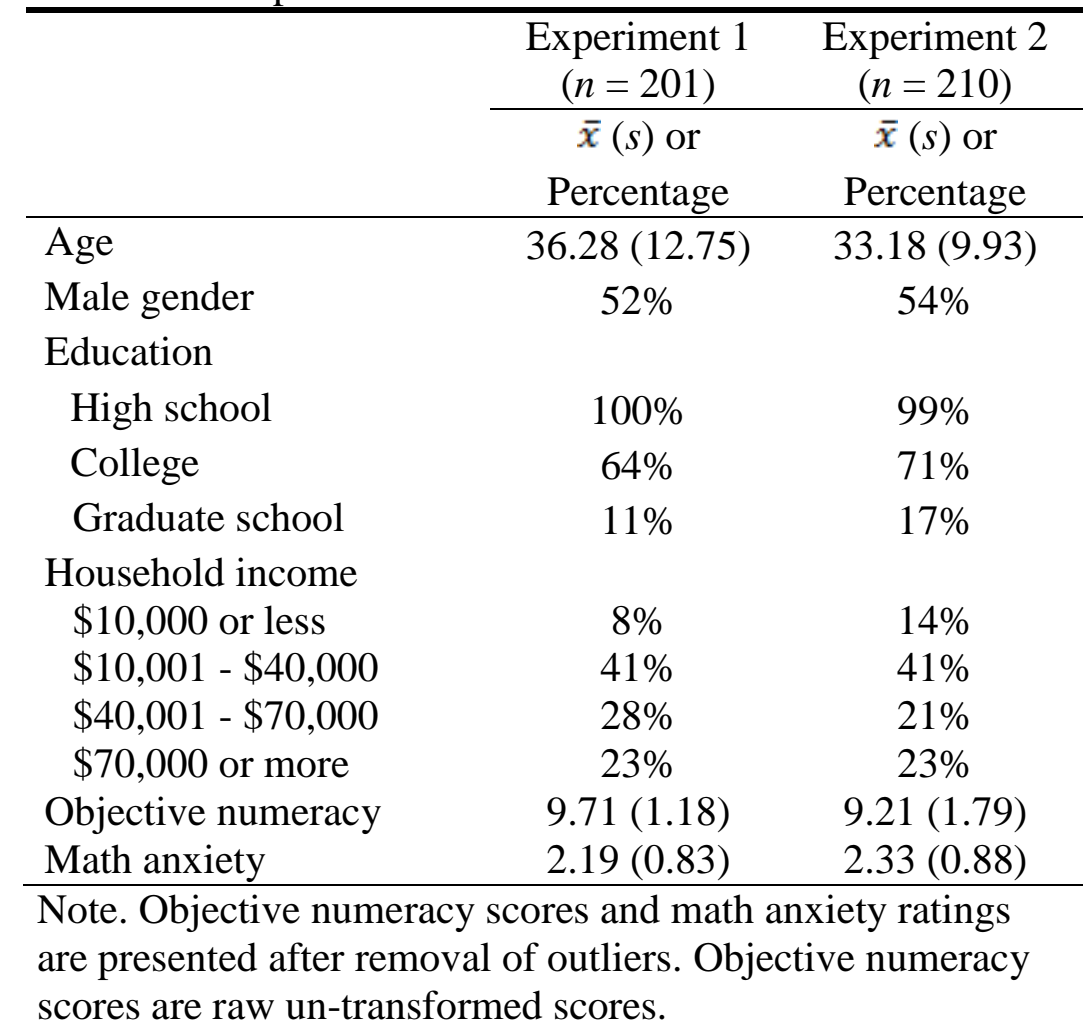

534

535

536

537

538

539

540

541 
Table 2. Adult Everyday Math Anxiety Scale (AEMAS) Items

In the following you will be presented with some everyday situations. Please rate each item in terms of how anxious you would feel during the event specified (1=low anxiety, $2=$ some anxiety, $3=$ moderate anxiety, $4=$ quite a bit of anxiety, $5=$ high anxiety)

1. Having to work with fractions

Experiment 1

Experiment 2

2. Having to work with percentages

3 . Having to work out a $15 \%$ tip

4. Figuring out how much a shirt will cost if it is $25 \%$ off

5. Having to work out prices in a foreign currency

6. Looking at tables and graphs when reading the newspaper

7. Being presented with numerical information about different mobile phone subscription options

8. Having to choose between financial investment options

9. Reading your bank's leaflet about changes in the terms of using your credit card

10. Having to complete a math course as part of your work training.

11. Having to sit a numeracy test as part of a job application process.

12. Having to present numerical information at a work meeting

13. Making an important decision at your workplace based on last year's statistics

$\begin{array}{llllll}2.93 & 1.21 & .65 & 2.85 & 1.16 & .56 \\ 2.31 & 1.18 & .61 & 2.38 & 1.16 & .65 \\ 2.38 & 1.27 & .80 & 2.51 & 1.28 & .76 \\ 2.68 & 1.33 & .78 & 2.67 & 1.31 & .77 \\ 2.43 & 1.28 & .77 & 2.59 & 1.25 & .76 \\ 2.61 & 1.17 & .75 & 2.63 & 1.21 & .73\end{array}$

542

543

544

545

546

547

548

549

550 
Table 3. Pearson correlations

\begin{tabular}{|c|c|c|c|c|c|c|c|c|c|c|}
\hline & \multicolumn{10}{|c|}{ Experiment 1} \\
\hline & $(1)$ & (2) & (3) & (4) & $(5)$ & $(6)$ & $(7)$ & (8) & (9) & (10) \\
\hline Age (1) & - & & & & & & & & & \\
\hline Male Gender (2) & -.07 & - & & & & & & & & \\
\hline Education (3) & .08 & -.08 & - & & & & & & & \\
\hline Income (4) & .10 & -.02 & .13 & - & & & & & & \\
\hline Objective numeracy (5) & .09 & .13 & .13 & $.18^{*}$ & - & & & & & \\
\hline Math anxiety (6) & .01 & $-.26 * *$ & $-.16^{*}$ & $-.14 *$ & $-.37 * *$ & - & & & & \\
\hline Baseline Risk (7) & $-.14 *$ & $.14 *$ & $.14 *$ & .01 & $.17 *$ & $-.20 *$ & - & & & \\
\hline Absolute Risk (8) & -.11 & .13 & -.05 & .08 & $.25 * *$ & $-.24 * *$ & $.36 * *$ & - & & \\
\hline Relative Risk (9) & .07 & .11 & .04 & .04 & $.25 * *$ & -.09 & $.16^{*}$ & .01 & - & \\
\hline Absolute Confidence (10) & -.11 & $.23 * *$ & .06 & .03 & $.35 * *$ & $-.32 * *$ & $.44 * *$ & $.36 * *$ & $.19^{*}$ & - \\
\hline \multirow[t]{3}{*}{ Relative Confidence (11) } & -.10 & $.23 * *$ & .09 & .07 & $.33 * *$ & $-.40 * *$ & $.41 * *$ & $.31 * *$ & .12 & $.86^{* *}$ \\
\hline & \multicolumn{10}{|c|}{ Experiment 2} \\
\hline & $(1)$ & $(2)$ & (3) & $(4)$ & $(5)$ & $(6)$ & $(7)$ & $(8)$ & $(9)$ & $(10)$ \\
\hline Age (1) & - & & & & & & & & & \\
\hline Male Gender (2) & $-.16^{*}$ & - & & & & & & & & \\
\hline Education (3) & .00 & -.06 & - & & & & & & & \\
\hline Income (4) & .09 & -.06 & .02 & - & & & & & & \\
\hline Objective numeracy (5) & -.07 & $.15^{*}$ & -.08 & .09 & - & & & & & \\
\hline Math anxiety (6) & .01 & $-.21 *$ & .02 & .04 & $-.50 *$ & - & & & & \\
\hline Baseline Risk (7) & .00 & .04 & -.03 & -.01 & .12 & $-.28 *$ & - & & & \\
\hline Treatment A Risk (8) & -.07 & .06 & -.08 & -.01 & $.22 *$ & $-.24 *$ & $.54 * *$ & - & & \\
\hline Treatment B Risk (9) & .07 & .04 & -.05 & -.03 & $.21 *$ & $-.14 *$ & $.33 * *$ & $.64 * *$ & - & \\
\hline Treatment A Confidence (10) & $-.16^{*}$ & $.17 *$ & .10 & .01 & $.39 * *$ & $-.43 * *$ & $.21 *$ & $.18^{*}$ & $.19 *$ & - \\
\hline Treatment B Confidence (11) & $-.14 *$ & $.22 *$ & $.14 *$ & .00 & $.38 * *$ & $-.43 * *$ & $.19^{*}$ & $.19 *$ & $.22 * *$ & $.89 * *$ \\
\hline
\end{tabular}

$551 \quad$ Note. $* p \leq .05, * * p \leq .001$. Baseline, absolute, relative risks are total correct risk

552 responses.

553

554

555

556

557

558

559

560

561

562

563 
Table 4. Logistic regression models used to predict correct responding

Experiment 1

Odds ratio $(95 \% \mathrm{CI})$
Experiment 2

Odds ratio $(95 \% \mathrm{CI})$

\begin{tabular}{|c|c|c|c|c|c|c|c|}
\hline & & & & & & & \\
\hline Included & Model 1a & Model 2a & Model 3a & Included & Model 1b & Model 2b & Model 3b \\
\hline Objective & $3.61 * *$ & & $3.07 * *$ & Objective & $4.57 * *$ & & $3.60 *$ \\
\hline Numeracy & $(2.16: 6.02)$ & & $(1.79: 5.27)$ & Numeracy & (1.84: 11.32) & & (1.30: 9.93) \\
\hline $\begin{array}{l}\text { Math } \\
\text { anxiety }\end{array}$ & & $\begin{array}{c}0.51 * * \\
(0.36: 0.71)\end{array}$ & $\begin{array}{c}0.76 \\
(0.54: 1.06)\end{array}$ & $\begin{array}{l}\text { Math } \\
\text { anxiety }\end{array}$ & & $\begin{array}{c}0.29 * * \\
(0.15: 0.56)\end{array}$ & $\begin{array}{c}0.71 \\
(0.35: 1.45)\end{array}$ \\
\hline Baseline & $22.45^{* *}$ & $22.00 * *$ & $22.42 * *$ & Baseline & $4.37 * *$ & $\begin{array}{l}4.59 * * \\
\end{array}$ & $4.37 * *$ \\
\hline risk & (12.97: 38.88) & $(12.72: 38.05)$ & $(12.95: 38.80)$ & risk & (2.06: 9.29) & $(2.20: 9.60)$ & (2.06: 9.29) \\
\hline $\begin{array}{l}\text { Relative } \\
\text { risk }\end{array}$ & $\begin{array}{c}0.11 * * \\
(0.07: 0.17)\end{array}$ & $\begin{array}{c}0.11 * * \\
(0.07: 0.17)\end{array}$ & $\begin{array}{c}0.11 * * \\
(0.07: 0.17)\end{array}$ & Treatment B & $\begin{array}{c}3.07 * \\
(1.51: 6.28)\end{array}$ & $\begin{array}{c}2.74^{*} \\
(1.38: 5.44)\end{array}$ & $\begin{array}{c}3.07 * \\
(1.51: 6.28)\end{array}$ \\
\hline $\begin{array}{l}\text { Scenario } \\
\text { context }\end{array}$ & $\begin{array}{c}1.26 \\
(0.90: 1.76)\end{array}$ & $\begin{array}{c}1.26 \\
(0.90: 1.75)\end{array}$ & $\begin{array}{c}1.26 \\
(0.90: 1.76)\end{array}$ & Display & $\begin{array}{c}0.48 \\
(0.16: 1.43)\end{array}$ & $\begin{array}{c}0.73 \\
(0.24: 2.21)\end{array}$ & $\begin{array}{c}0.52 \\
(0.18: 1.57)\end{array}$ \\
\hline
\end{tabular}

564 Note. $* p \leq .05, * * p \leq .001$. In Experiment 1, the baseline and relative risk are in comparison

565 to the absolute risk. In Experiment 2, the baseline and Treatment B risk are in comparison to

566 the Treatment A risk. $R_{\text {McFadden }}^{2}$ Model $1 \mathrm{a}=0.37$, Model $2 \mathrm{a}=0.35$, Model $3 \mathrm{a}=0.37$, Model

$5671 \mathrm{~b}=0.15$, Model $2 \mathrm{~b}=0.06$, Model $3 \mathrm{~b}=0.15$.

568

569

570

571

572

573

574

575

576

577

578

579

580

581

582

583 
Table 5. Linear regression models used to predict confidence ratings

\begin{tabular}{lcclccc}
\hline & \multicolumn{2}{c}{ Experiment 1} & & \multicolumn{2}{c}{ Experiment 2 } \\
& Unstandardized beta $(95 \% \mathrm{CI})$ & & \multicolumn{2}{c}{ Unstandardized beta $(95 \% \mathrm{CI})$} \\
\cline { 2 - 4 } Included & Model 1a & Model $2 \mathrm{a}$ & Included & & Model 1b & Model $2 \mathrm{~b}$ \\
\hline Objective & $0.86^{* *}$ & $0.86^{* *}$ & Objective & & $0.54^{*}$ & $0.51^{*}$ \\
Numeracy & $(0.39: 1.34)$ & $(0.39: 1.34)$ & Numeracy & & $(0.12: 0.97)$ & $(0.10: 0.93)$ \\
Math anxiety & $-0.59^{* *}$ & -0.32 & Math anxiety & $-0.62^{* *}$ & $-1.58^{* *}$ \\
& $(-0.90:-0.29)$ & $(-0.70: 0.07)$ & & $(-.86:-0.37)$ & $(-2.25:-0.91)$ \\
Relative risk & $-0.32^{* *}$ & 0.09 & Treatment B & $0.15^{*}$ & $0.15^{*}$ \\
& $(-0.45:-0.19)$ & $(-0.28: 0.45)$ & & $(0.05: 0.25)$ & $(0.05: 0.25)$ \\
Scenario context & 0.01 & 0.01 & Display & $0.41^{*}$ & $-1.04 *$ \\
& $(-0.12: 0.14)$ & $(-0.12: 0.14)$ & & $(0.05: 0.77)$ & $(-2.05:-0.03)$ \\
Math anxiety x & & $-0.19^{*}$ & Display x Math & & $0.62^{*}$ \\
relative risk & & $(-0.34:-0.03)$ & Anxiety & & $(0.22: 1.03)$
\end{tabular}

584 Note. $* p \leq .05, * * p \leq .001$. The relative risk is comparison to the absolute risk in 585 Models 1a and 2a. The Treatment B risk is in comparison to the Treatment A risk in 586 Models $1 \mathrm{~b}$ and 2b. $R^{2}$; Model $1 \mathrm{a}=0.16$, Model $2 \mathrm{a}=0.16$, Model $1 \mathrm{~b}=0.22$,

587 Model 2b $=0.26$.

588

589

590

591

592

593

594

595

596

597

598

599

600

601

602

603 
Treatment A: The patient's chance of surviving one year is increased TO $80 \%$.

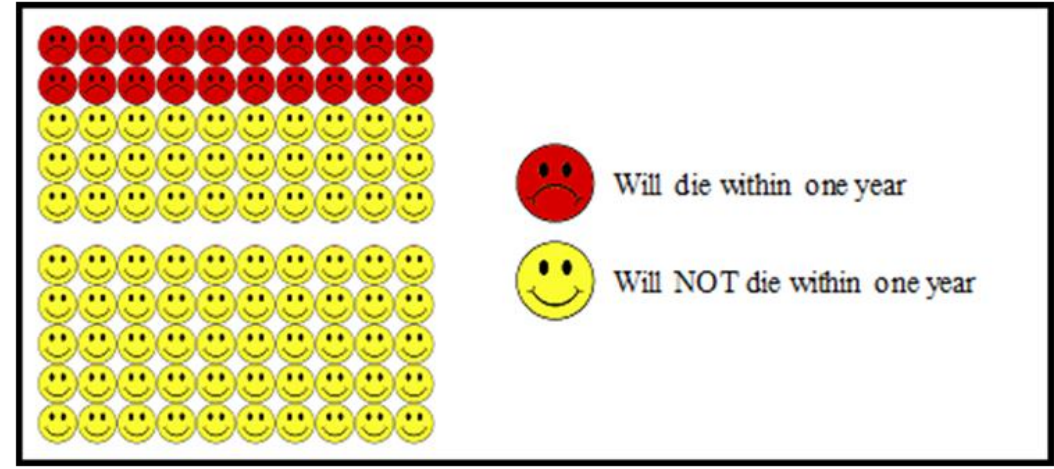

Treatment B: The patient's chance of surviving one year is increased TO $70 \%$.

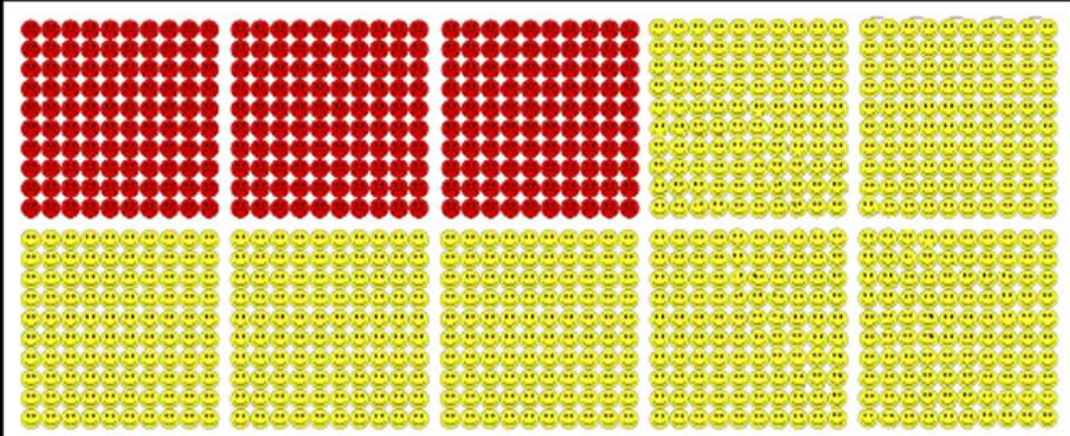

Will die within one year

Uill NOT die within one year

605 Figure 1. An example of the graphical display presented to participants in Experiment 2. The

606 absolute risk reduction is displayed out of 100 patients for Treatment A and out of 1,000

607 participants for Treatment B. Participants were asked for each treatment how many patients

608 among 1,000 would die.

609 